\title{
Manufacturing and Evaluation of Multi-Material Axial-Bearing Washers by Tailored Forming
}

\author{
Bernd-Arno Behrens ${ }^{1}$, Alexander Chugreev ${ }^{1}$, Tim Matthias ${ }^{1, *}$, Gerhard Poll ${ }^{2}$, Florian Pape ${ }^{2}$, \\ Timm Coors ${ }^{2}$, Thomas Hassel ${ }^{3}$, Hans Jürgen Maier ${ }^{3}$ and Maximilian Mildebrath ${ }^{3}$ \\ 1 Institute of Forming Technology and Machines, Leibniz University Hannover, 30823 Garbsen, Germany; \\ behrens@ifum.uni-hannover.de (B.-A.B.); chugreev@ifum.uni-hannover.de (A.C.) \\ 2 Institute of Machine Design and Tribology, Leibniz University Hannover, 30167 Hanover, Germany; \\ poll@imkt.uni-hannover.de (G.P.); pape@imkt.uni-hannover.de (F.P.); coors@imkt.uni-hannover.de (T.C.) \\ 3 Institute of Materials Science, Leibniz University Hannover, 30823 Garbsen, Germany; \\ hassel@iw.uni-hannover.de (T.H.); maier@iw.uni-hannover.de (H.J.M.); \\ mildebrath@iw.uni-hannover.de (M.M.) \\ * Correspondence: tmatthias@ifum.uni-hannover.de; Tel.: +49-511-762-3405
}

Received: 21 December 2018; Accepted: 9 February 2019; Published: 15 February 2019

\begin{abstract}
Components subject to rolling contact fatigue, such as gears and rolling bearings, are among the fundamental machine elements in mechanical and vehicle engineering. Rolling bearings are generally not designed to be fatigue-resistant, as the necessary oversizing is not technically and economically marketable. In order to improve the load-bearing capacity, resource efficiency and application possibilities of rolling bearings and other possible multi-material solid components, a new process chain was developed at Leibniz University Hannover as a part of the Collaborative Research Centre 1153 "Tailored Forming". Semi-finished products, already joined before the forming process, are used here to allow a further optimisation of joint quality by forming and finishing. In this paper, a plasma-powder-deposition welding process is presented, which enables precise material deposition and control of the welding depth. For this study, bearing washers (serving as rolling bearing raceways) of a cylindrical roller thrust bearing, similar to type 81212 with a multi-layer structure, were manufactured. A previously non-weldable high-performance material, steel AISI 5140, was used as the cladding layer. Depending on the degree of forming, grain-refinement within the welded material was achieved by thermo-mechanical treatment of the joining zone during the forming process. This grain-refinements lead to an improvement of the mechanical properties and thus, to a higher lifetime for washers of an axial cylindrical roller bearing, which were examined as an exemplary component on a fatigue test bench. To evaluate the bearing washers, the results of the bearing tests were compared with industrial bearings and deposition welded axial-bearing washers without subsequent forming. In addition, the bearing washers were analysed micro-tribologically and by scanning acoustic microscopy both after welding and after the forming process. Nano-scratch tests were carried out on the bearing washers to analyse the layer properties. Together with the results of additional microscopic images of the surface and cross-sections, the causes of failure due to fatigue and wear were identified.
\end{abstract}

Keywords: tailored forming; hybrid bearing; deposition welding

\section{Introduction and Motivation}

Depending on operating conditions, some regions of machine components are exposed to higher mechanical, chemical or thermal stresses than others. For example, due to tribological contact under cyclic loads, the contacting surfaces are more highly stressed compared to the rest of the part. 
This requires using high performance, but at the same time cost-intensive materials, in order to meet the technical demands. In this context, conventional mono-material components consisting of the same high strength material within the whole component volume are not resource efficient. In contrast, a multi-material approach offers ample potential for efficient material utilization by applying different materials in a single component. For reducing material costs and energy consumption during the components service life, lightweight and less expensive material can be used in regions apart from the highly stressed zones. By combining individual benefits of several materials in one component, it is possible to produce multi-material parts with extended functionality and specific property profiles optimized according to the predominant load collective [1]. Motivated by this objective, the developing of new concepts to produce multi-material components has been gaining in importance in recent years.

\section{Process Chain for the Manufacture of a Hybrid Axial Bearing Washer}

The Collaborative Research Center (CRC) 1153 "Tailored Forming" aims to develop the potential for hybrid solid components on the basis of a novel process chain and to develop the necessary manufacturing processes. In contrast to existing manufacturing processes for hybrid solid components, in which the joining process only takes place during forming or at the end of the manufacturing chain, the CRC uses tailor-made semi-finished products that are joined before the forming process. In this way, components can be produced in a way that meets the required specifications of the different structural and functional areas in the component much better than components made of mono-materials. By combining different materials within a component, the weight of the component can be reduced either by the local use of lightweight materials or by reducing the costs of the component by combining them with high-quality alloys. Compared to existing manufacturing processes, the simple geometry of the semi-finished products in the tailored forming process chain facilitates handling and the reliable production of a material-locking joining zone. The specifically controlled material flow during the subsequent forming also enables the resulting joining zone geometry to be influenced, which is currently not feasible with conventional joining processes. The thermo-mechanical influence during forming also improves the quality of the joining zones.

This paper focuses on the development of a process chain for the manufacture of an axial bearing consisting of the matrix material AISI $1022 \mathrm{M}$ as well as of the low-alloy quenched and tempered steel AISI 5140. This process chain is shown schematically in Figure 1. In the first step, tailored forming is used to produce the hybrid semi-finished product by means of plasma transferred arc powder deposition (PTA) welding (Figure 1a). With the aid of forging (Figure 1b) of the hybrid workpiece, the semi-finished product is then formed near-net-shape. In the further course of the process chain, additional processing steps, such as heat treatment and machining (Figure 1c), are carried out until the finished hybrid component is completed (Figure 1d).

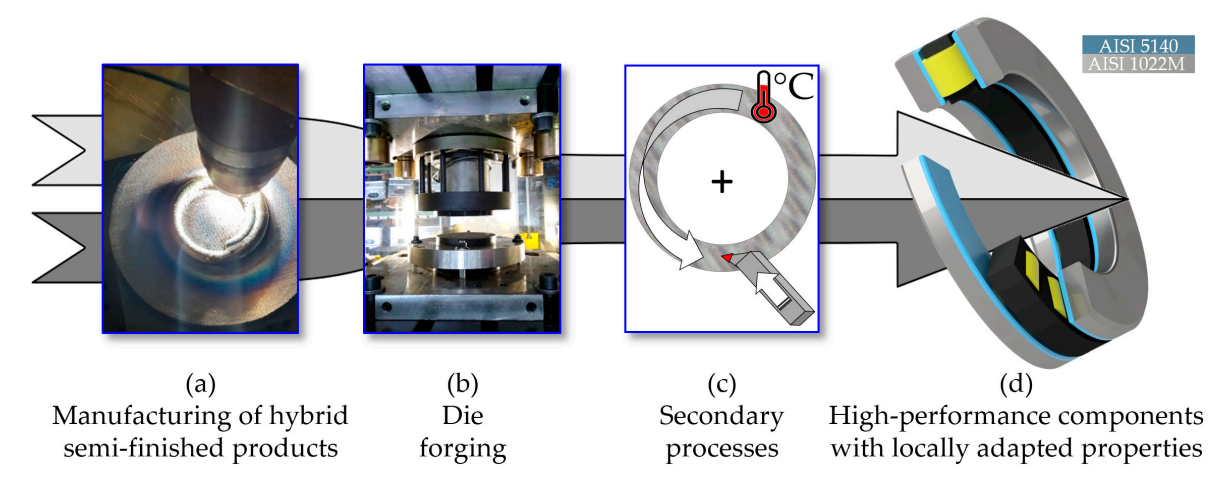

Figure 1. Process chain for manufacturing a hybrid axial bearing washer by tailored forming. (a) Plasma-transferred arc deposition welding, (b) hot forming, (c) mechanical processing and heat treatment, (d) Bearing assembly for use in a test bench. 
Blohm et al. [2] formed shafts of low-alloyed steel in a cross-wedge rolling process, which were beforehand cladded with heat-treated steel by PTA welding. It turned out that no defects occurred in the joint. Mildebrath et al. [3] examined hot-formed components which had previously been coated with a PTA-welding process. It could be shown that low-alloy steels recrystallize completely as a result of the forming process. Therefore, changes in the microstructure introduced by the welding process, which are generally regarded as disadvantageous, are negligible. However, the presence of pores is the greatest risk of failure during operation on the microstructure regarding tribologically loaded components reinforced by PTA cladding without subsequent forming [4]. In the work of Behrens et al. [5], a numerical tool system was designed to produce hybrid bevel gears by tailored forming, which had previously been joined by deposition welding. In addition to the numerical process design, the necessary material characterization, the first results of the experimental forging investigations as well as the resulting metallographic analyses were presented. It was shown that the hybrid bevel gears had no forging defects (e.g., pores) due to optimal die filling. More in-depth metallographic analyses have been carried out by Chugreeva et al. [6]. In addition to flawless surfaces and joining zones, it was also observed that a significant grain refinement in both materials after the forging process due to a thermomechanical treatment of the joining zone during the forming process occurs. This effect of grain refinement is intended to further optimize the mechanical properties of the component. Fatigue tests at component level for tailored forming machine elements were conducted in earlier work [7]. The subsequent forming process showed an improvement in bearing fatigue life for different tailored forming components by improving the joining zone quality. From the literature, numerical and experimental studies are known for deviating sample geometries produced by laser cladding without subsequent forming [8,9].

\section{Methodology for the Production of Hybrid Axial Bearing Washers}

In this context, this paper presents a new method for the manufacturing of multi-material components by means of tailored forming, which is exemplarily applied on an axial bearing washer (see Figure 1). The process chain begins with the joining of different materials with simple geometries to a multi-material semi-finished workpiece. The previously joined workpieces are subsequently formed in order to produce the near-net-shape geometry but also to enhance the microstructure and resulting properties in the joining zone. The processes that follow, such as machining and heat treatment, finalise the process chain.

In the context of rolling bearings, the term "hybrid" is usually used for bearings in which different materials are used for the bearing rings and the rolling elements [10]. The most common type is a deep groove ball bearing with conventional bearing rings made of nitrided bearing steel and balls made of a high-strength ceramic, usually silicon nitride [11]. These bearings are used for high performance applications and are complex with regard to their proper evaluation [12]. In the context of this article, however, the term "hybrid" is used synonymously for multi-material components under the influence of rolling contact fatigue.

Within the scope of this study, the production process and properties of hybrid axial bearing washers are investigated. They consist of the basic material AISI 1022M and the wear-resistant cladding AISI 5140 and are serving as a raceway for cylindrical roller thrust bearings similar to type 81212 . The hybrid bearing washers are combined with conventional industrial rolling elements made of monolithic AISI 52100 with a carbon equivalent of CEV $>1$. This steel cannot be welded defect-free with actual joining processes. Due to the lower material fatigue strength of the AISI 5140 material used, a lower service life is therefore expected than compared to bearing washers made from conventional bearing steel. Having in mind that the process of "Tailored Forming" allows to prepare machine elements with tailored properties, the described process makes sense as a bearing can be integrated to a shaft by reinforcing discrete areas by higher strength materials. To achieve beneficial surface properties after deposition, a forming step is mandatory. In case of a high throughput of machine elements like a tailored forming drive shaft or a large size bearing it is expected that "Tailored Forming" 
is competitive. In our case, the thrust bearings are used as an analogy part to achieve knowledge in the tailored forming process route and to investigate the fatigue strength of these parts compared to conventional bearings. However, it is not the target to beat the current industrial standard for small bearings, but to show the high potential of the Tailored Forming concept.

In the following, the manufacturing processes are investigated. In order to compare the results, various produced hybrid bearing washers were subjected to uniform heat treatment and machining post-processing. The properties are evaluated by metallographic examinations, (micro-) tribological tests and non-destructive testing methods. A distinction is made between build-up welded axial bearing washers without and with subsequent forming. This is intended to highlight the advantages of tailored forming technology.

\section{Production of Axial-Bearing Washers with Tailored Properties by Plasma Transferred Arc Deposition Welding}

Deposition welding is a particularly efficient process for applying high-performance metallic cladding to substrate materials to improve surface properties. In this way, hybrid steel components can be produced flexibly in dependence on the welding process used. There are various processes for deposition welding which have different advantages and are currently used in the industry. These include metal inert gas welding, submerged arc deposition welding, plasma powder deposition welding (PTA), laser deposition welding [13] and electroslag welding [14]. For maximum flexibility, a process that uses powder as a filler material is best suited. The majority of materials, which achieve maximum hardness when welded, are available as powders, since the production of solid welding rods from these materials is proven to be difficult. This is particularly true for low-alloy quenched and tempered steels with high carbon equivalent $(\mathrm{CEV}>0.5)$. Welding processes with these materials are generally challenging, since these materials are classified as non-weldable or difficult to weld according to the current material data sheets [15]. Nevertheless, it is possible to process these materials with PTA welding, which is why the process is well suited for this aim.

In the PTA welding process, an arc burns between a non-melting tungsten electrode and the workpiece. The powdery filler material is blown into the arc and reaches the workpiece completely molten. Argon is used as protective gas. The process can be automated very well by robots and enables application rates of up to $10 \mathrm{~kg} / \mathrm{h}$ [15].

In general, there is a lot of literature on plasma powder deposition welding for welding hard materials onto steel substrates in which the wear properties of new alloys for deposition cladding are primarily investigated. The influences of process parameters such as current, powder feed rate and welding speed on the dilution are also examined. A focus on the component temperature of the substrate material is not common as an influencing factor.

Motallebzadeh et al. [16] welded a hypo-eutectic hard material alloy to a steel substrate and conducted investigations on the microstructure and tribological performance. Ferozhkhan et al. [17] welded a stellite 6 alloy onto a stainless-steel substrate and carried out investigations on wear resistance. Sawant et al. [18] also welded a stellite 6 alloy to an AISI 4130 steel using micro plasma powder deposition welding. In this study the influence of the energy per unit length on the mixing and microstructure was investigated. Deng et al. [19] welded an iron-molybdenum alloy onto an AISI 1045 steel by PTA welding and investigated the microstructure.

The base material for the bearing washers is unalloyed steel AISI 1022M. The sample geometry, which is cladded, has the shape of discs with a diameter of $130 \mathrm{~mm}$ and a thickness of $11 \mathrm{~mm}$. The steel AISI 1022M is usually used as a construction material in general mechanical engineering and in vehicle construction. The chemical composition is shown in Table 1.

The low-alloy quenched and tempered steel AISI 5140 is used as the cladding material for PTA welding. The steel is considered difficult to weld and achieves tensile strengths of 800-1000 MPa. AISI 5140 is primarily used for drive parts such as crankshafts, front axles and steering parts. The chemical composition can be found in Table 2. 
Table 1. Chemical composition in wt. \% of AISI 1022M.

\begin{tabular}{cccccc}
\hline C & Si & Mn & P & S & Cr \\
\hline $0.17-0.24$ & $<0.40$ & $0.40-0.70$ & $<0.045$ & $<0.045$ & $<0.40$ \\
\hline
\end{tabular}

Table 2. Chemical composition in wt.\% of AISI 5140.

\begin{tabular}{cccccc}
\hline $\mathbf{C}$ & $\mathbf{S i}$ & $\mathbf{M n}$ & $\mathbf{P}$ & $\mathbf{S}$ & $\mathbf{C r}$ \\
\hline $0.38-0.42$ & $<0.40$ & $0.60-0.90$ & $<0.025$ & $<0.035$ & $<0.90-1.20$ \\
\hline
\end{tabular}

The powder is filtered with a sieving unit. Only powder consisting of metal grains with a diameter of minimum $50 \mu \mathrm{m}$ to maximum $150 \mu \mathrm{m}$ is used for welding. This corresponds to the current industrial standard for additional materials in powder form that are used for welding. The welding process is carried out on a 6-axis REIS RV-16 industrial robot (Reis Robotics GmbH, Obernburg am Main, Germany) with a tilt and turn table. The PTA torch that is used is the Kennametal Stellite HPM 302 (Deloro Wear Solutions, Koblenz, Germany), the current source is the Stellite Starweld PTA 302 (Deloro Wear Solutions, Koblenz, Germany). The welding equipment can be seen in Figure 2a.

(a)

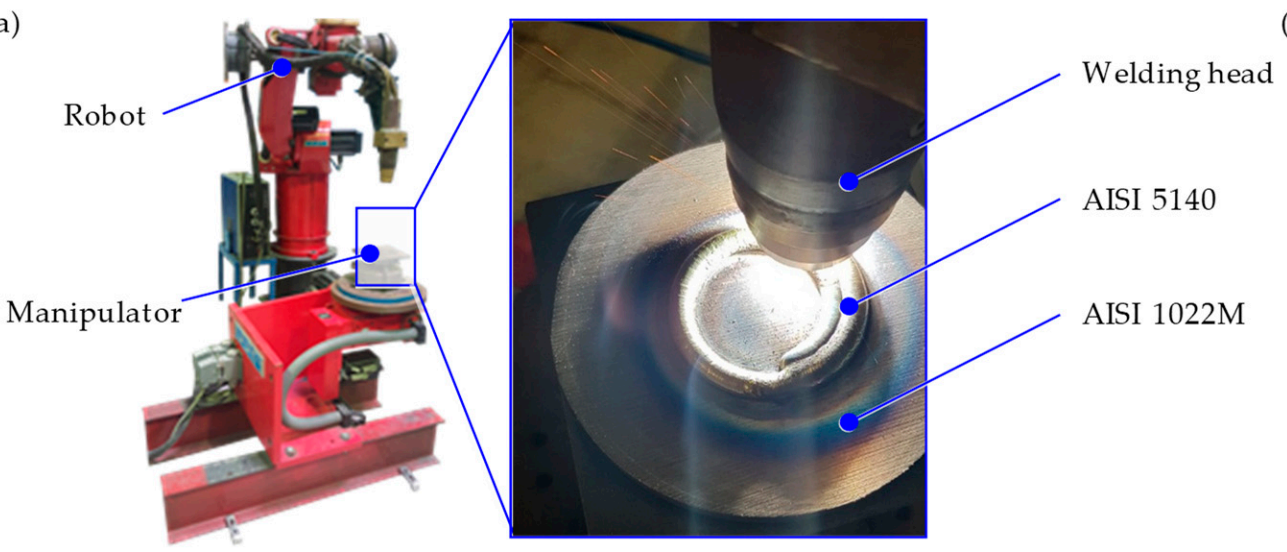

(b)

Figure 2. Experimental setup of PTA welding (a), PTA-process (b).

The discs are cut with a water-cooled band saw from a long round steel. After sawing, the surfaces of the discs are cleaned with acetone. There is no further surface treatment before welding. To coat the discs, AISI 5140 is welded in a spiral until the surface of the bearing track is fully coated. This process can be seen in Figure 2b. The entire welding process takes a total of $10 \mathrm{~min}$ and $35 \mathrm{~s}$, which leads to a strong heating of the disc to up to $650{ }^{\circ} \mathrm{C}$. With constant welding parameters, this strong heating leads to an ever-increasing material dilution between the cladding material and the substrate. Therefore, the current is slowly reduced from $180 \mathrm{~A}$ at the beginning of the welding process to only $130 \mathrm{~A}$ at the end of the process in order to keep the dilution as low and constant as possible. The exact course of the current intensity in the PTA welding process is shown in Figure 3.

In order to apply the seam as homogeneously as possible and to avoid pores, the welding torch oscillates over a short distance of $4 \mathrm{~mm}$ with a frequency of $2 \mathrm{~Hz}$ at an angle of $90^{\circ}$ to the welding direction. This slightly increases the dynamics of the weld pool and allows gases contained in the melt to escape more easily, which reduces pore formation. An overview of the general welding parameters can be found in Table 3. 


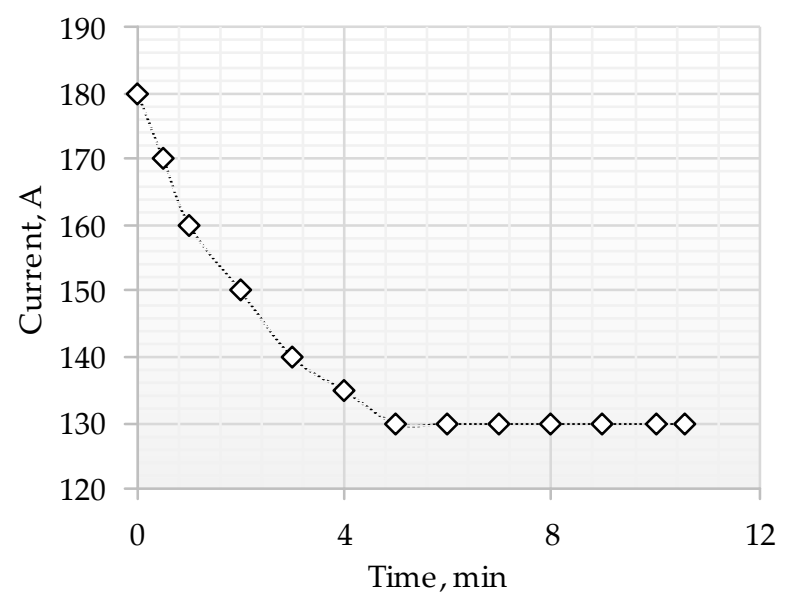

Figure 3. Current intensity curve during cladding process.

Table 3. Welding parameters.

\begin{tabular}{cc}
\hline Parameter & Value \\
\hline Shielding gas flow (Argon) & $10 \mathrm{~min}^{-1}$ \\
Plasma gas flow (Argon) & $1 \mathrm{~min}^{-1}$ \\
Transport gas flow (Argon) & $4 \mathrm{~min}^{-1}$ \\
Welding velocity & $2 \mathrm{~mm} / \mathrm{s}$ \\
Working Distance & $12 \mathrm{~mm}$ \\
Current & Dynamic, $180-130 \mathrm{~A}$ \\
Voltage & $25-27$ V (depends on current) \\
Powder material & AISI 5140 atomized under argon atmosphere \\
Grid size of powder particles & $0.05-0.15 \mathrm{~mm}$ (current industry standard) \\
Powder flow rate & $15 \mathrm{~g} / \mathrm{min}$ \\
\hline
\end{tabular}

\section{Forging of Hybrid Bearing Washers}

In order to improve the microstructure and mechanical properties of the welded material, the multi-material semi-finished workpieces were subsequently formed by die forging after the PTA welding. For the manufacturing of hybrid bearing washers, a single-stage forming process was developed. The die forging tests were performed on a hydraulic press with a maximum capacity of $12,000 \mathrm{kN}$ with a tool system depicted in Figure 4. Before forging, the bearing washers were heated up to the forging temperature of $1050^{\circ} \mathrm{C}$ in a chamber furnace. In order to determine the heating time, the initial heating tests with thermocouples integrated on the specimens were conducted. To prevent the oxidation of the welded layer at the heating stage, a gas flushing box was used, which was flooded with inert gas nitrogen during heating. After heating, the multi-material workpieces were manually transported to the forging tool and formed to the final geometry. The maximal pressing force of approx. $1700 \mathrm{kN}$ was measured by an integrated load cell. The height of the bearing washers was finally reduced to approx. $10 \mathrm{~mm}$. Following, the forged bearing washers were slowly cooled in the air.

After the forming process, the wavy surface morphology of the clad material resulting from the welding process was eliminated, shown by a surface analysis in Figure 5. For this purpose, an investigation of workpiece surfaces before and after forming was carried out on a confocal laser microscope Keyence VR-3200 (Keyence Deutschland GmbH, Neu-Isenburg, Germany). The measured vertical profiles are presented in the upper part of Figure 5. After the forging process, a significant surface flattening of the welded material was observed. 
(a)
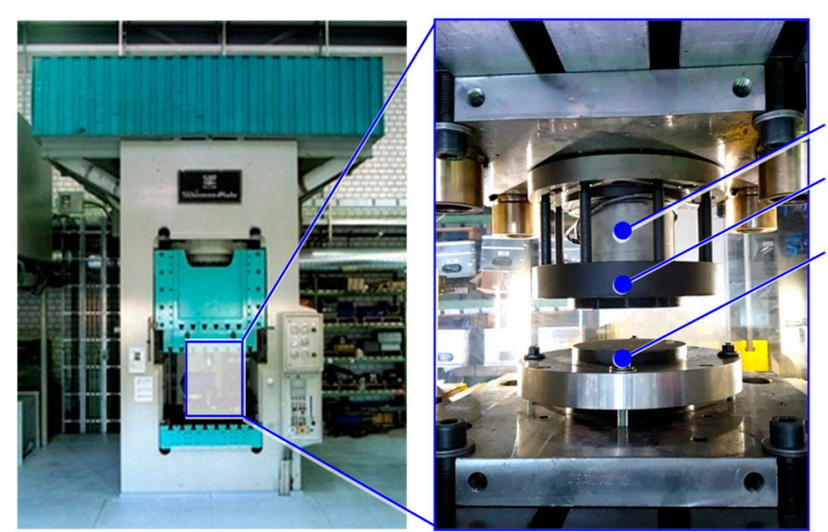

(b)

Load cell

Upper die

Lower die

Figure 4. Hydraulic forming press (a), forming tool system for forging of the bearing washers (b).

(a) Heightprofile, $\mathrm{mm}$

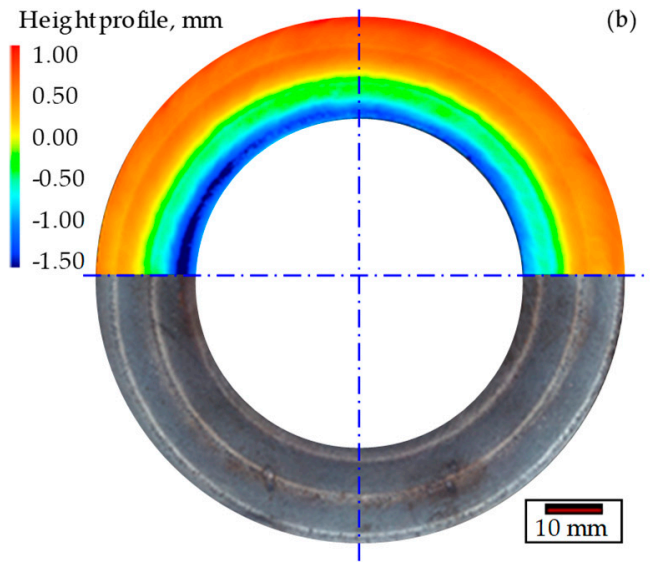

(b) Height profile, $\mathrm{mm}$

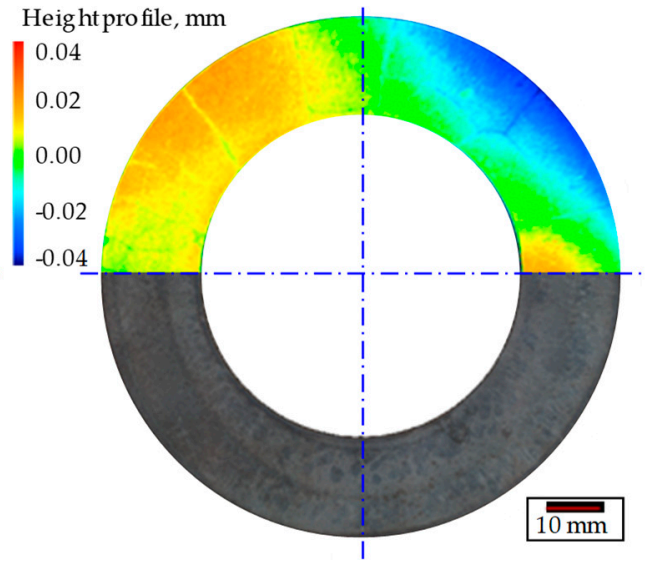

Figure 5. Height profile of the hard-faced area before (a) and after forging (b).

\section{Metallographic Investigations}

Moreover, a metallographic examination was carried out on samples extracted from the cladded bearing washers and forged bearing washers with and without subsequent targeted heat treatment. The microstructure of the substrate and clad material before forging is shown in Figure 6a. The substrate material AISI 1022M demonstrates a microstructure containing a mixture of ferrite and pearlite typically for the carbon steel. The proportion of ferrite (white regions) is higher compared to pearlite (dark regions). The microstructure of the clad material AISI 5140 is almost exclusively pearlitic, which can be seen very well by the fine black/white stripes in the cladding layer of Figure 6a.

The cross-section of the hybrid bearing washer after forging is shown in Figure $6 \mathrm{~b}$. After hot forming, the semi-finished discs were slowly cooled in air. Therefore, the base material and the cladding layer are ferritic/perlitic. However, due to the twice as high carbon content, the cladding layer has considerably more perlite than the base material. The structure of the cladding material is fine-grained and homogeneous. In comparison to the pictures of the welded samples, these pictures show that a complete microstructure recrystallization has taken place in the cladding layer. Disadvantageous microstructure formations, which can have a negative effect compared to the later type of loading and which are caused by the heat influence of the welding process, are dissolved by the forming process. This effect can be explained by thermal, mechanical and thermomechanical treatment during the warm forming which leads to improved mechanical properties and component quality as shown in previous research works [20].

The semi-finished washers were austenitized in an electrically heated chamber furnace in neutral annealing coal and under argon atmosphere at $860^{\circ} \mathrm{C}$ for $45 \mathrm{~min}$. The discs were then quenched in 
water. The discs were not tempered. The cross-section of the hybrid bearing washer after the hardening process is shown in Figure 6c. It can be seen clearly that the cladding layer is completely converted to martensite. This is also confirmed by the hardness test (640 HV1) in Figure 7 and the light color of the cut. Due to the high level of hardness, the martensite is more difficult to etch with the $2 \%$ nitric acid, hence the light colour. In the magnification of the micrograph, the mainly needle-like structure of the martensite can be seen in the application layer. Martensite has also formed in the base material. Due to the too low C-content, however, no higher hardness than $320 \mathrm{HV} 1$ can be achieved here. The base material therefore remains ductile compared to the cladding layer even after hardening.
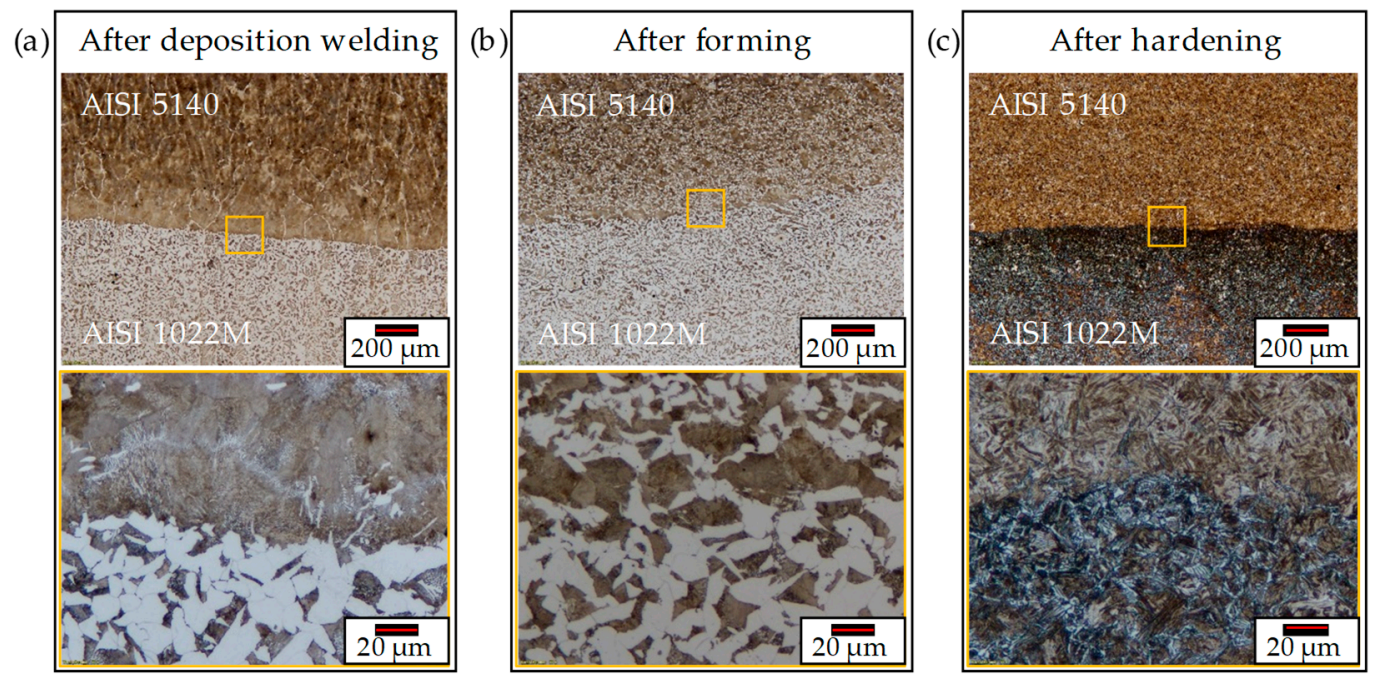

Figure 6. Micrograph of the joining zone after deposition welding (a), after forging (b) and after hardening (c).
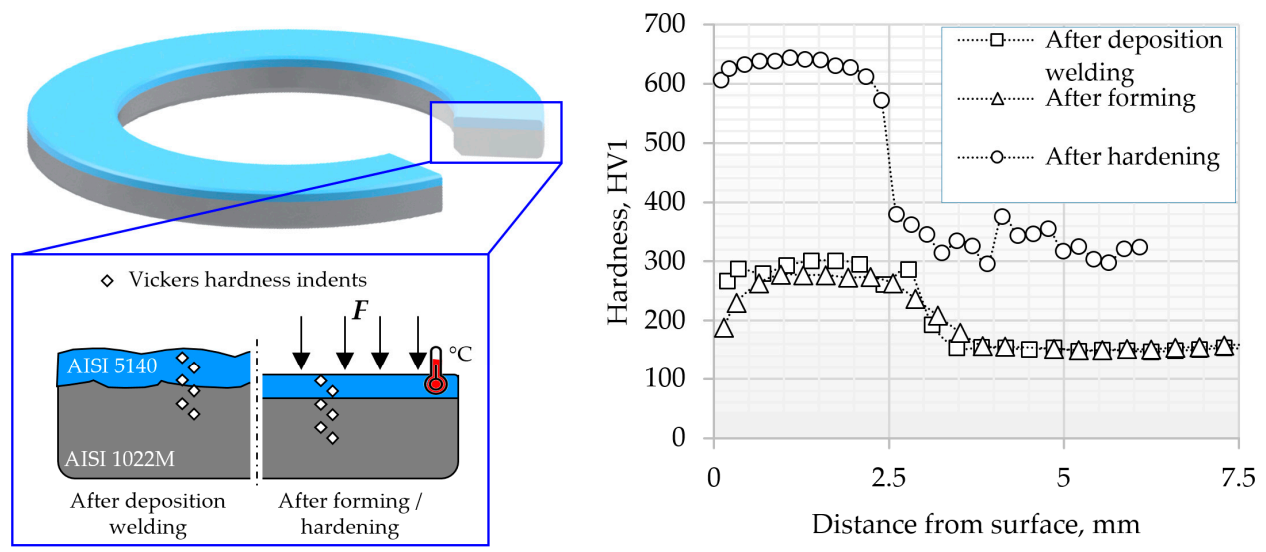

Figure 7. Hardness gradients of the hybrid bearing washers.

In addition, micro-hardness measurements were carried out. These are used to determine the hardening state of a material and its microstructural components. The hardness measurement was carried out based on the Vickers test with a four-sided diamond pyramid indent. The hardness of the three samples was respectively measured at the edge as well as in the middle of the sample. Figure 7 shows the hardness profile depths of the three samples: after deposition welding, after forming and after hardening.

The hardening results confirm the metallographic investigations from the previous chapter. Due to the thermomechanical stress during hot forming and the subsequent slow cooling in air, the hybrid bearing washer loses some of its hardness. The subsequent heat treatment made it possible to achieve hardness values comparable to those of the industrial bearings. As already described above, 
a hardness of $320 \mathrm{HV} 1$ was achieved in the AISI 1022M due to the low C-content. The base material therefore remains ductile even after the hardening process compared to the top layer.

\section{Microtribological Investigations}

The microtribological properties of the bearing washers were investigated before and after each process step using a nanoindenter. For this purpose, a Hysitron TriboIndenter TI 950 is used. Nano-scratch tests were carried out to determine the friction and mechanical surface properties. For this purpose, a cono-spherical diamond tip with a radius of $300 \mathrm{~nm}$ was used. The measured values can be used to determine the elastic and plastic deformation behaviour and the penetration-dependent friction value during ploughing. The cono-spherical indenter travels along the specimen surface with linearly increased normal load and constant speed. The normal force on the measuring tip can vary from $1 \mu \mathrm{N}$ to $10 \mathrm{mN}$ and is moved over the sample with electrostatic force resulting in a tangential force. As the normal force increases during furrowing (scratch test) also the tangential forces have to increase. The system detects by a change in capacitance the tangential force in dependence to the normal force and the displacement in depth. This allows us to calculate the coefficient of friction (CoF) $\mu$ while ploughing. A maximum load of $1 \mathrm{mN}$ was applied to the tip during the scratch tests. The surface profile was recorded before and after each scratch test using SPM (Scanning Probe Microscopy). The travel length of the tip on the surface was $8 \mu \mathrm{m}$. Each test was performed in three steps: initially, the surface contour was scanned by the tip under very low load on the scratch path (pre-scan). Next, the scratch was performed on the same route with a final force of $1 \mathrm{mN}$ (scratch). Finally, the plastically deformed material was analysed in a post-scan. The difference between the pre-scan and the post-scan curve allows the detection of the elastic and plastic deformation [21]. During the test, the coefficient of friction was evaluated. Figure 8 shows the measured surface properties of the hybrid bearing washers compared to the results of the axial bearings made of conventional AISI 52,100 bearing steel.
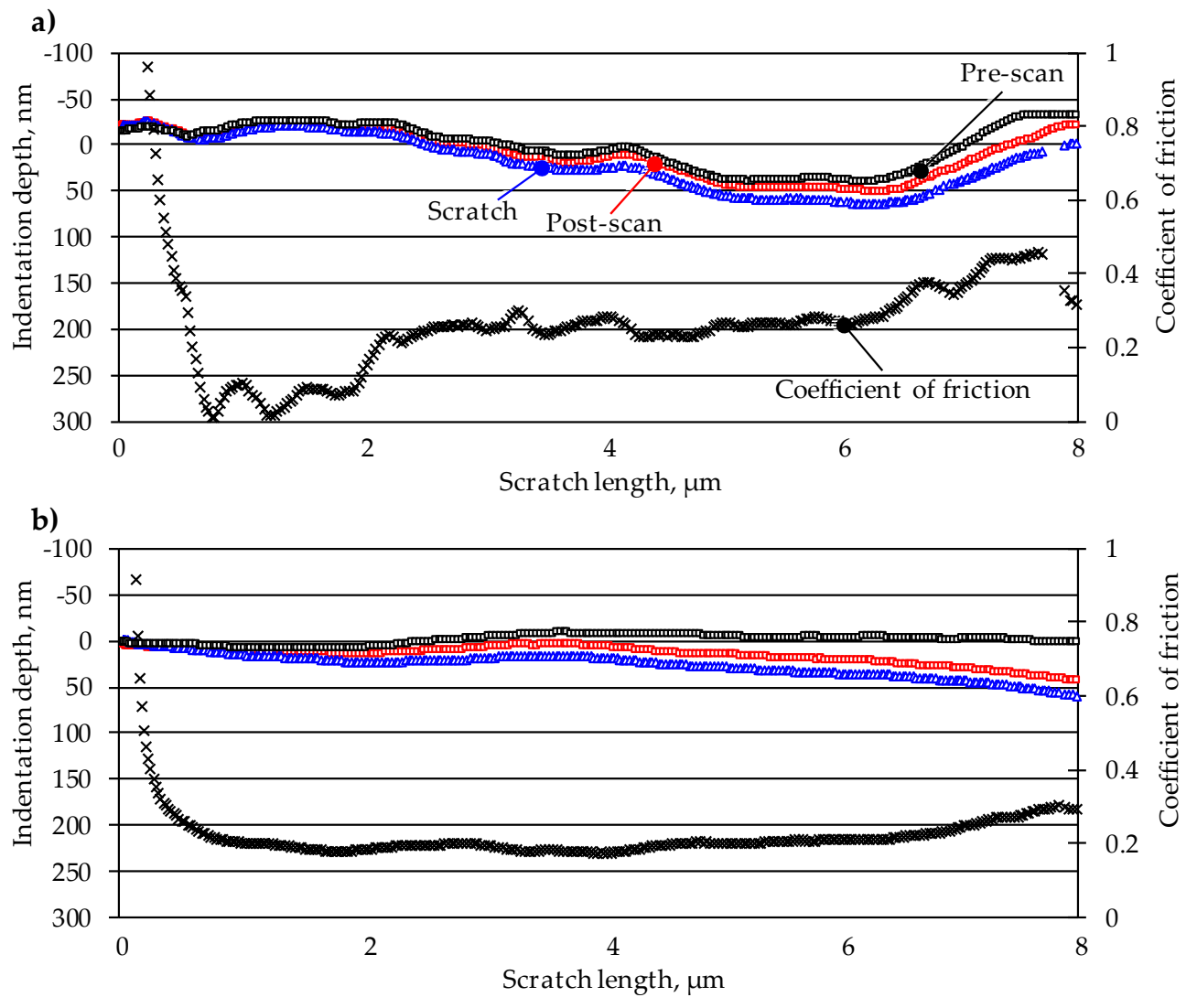

Figure 8. Cont. 


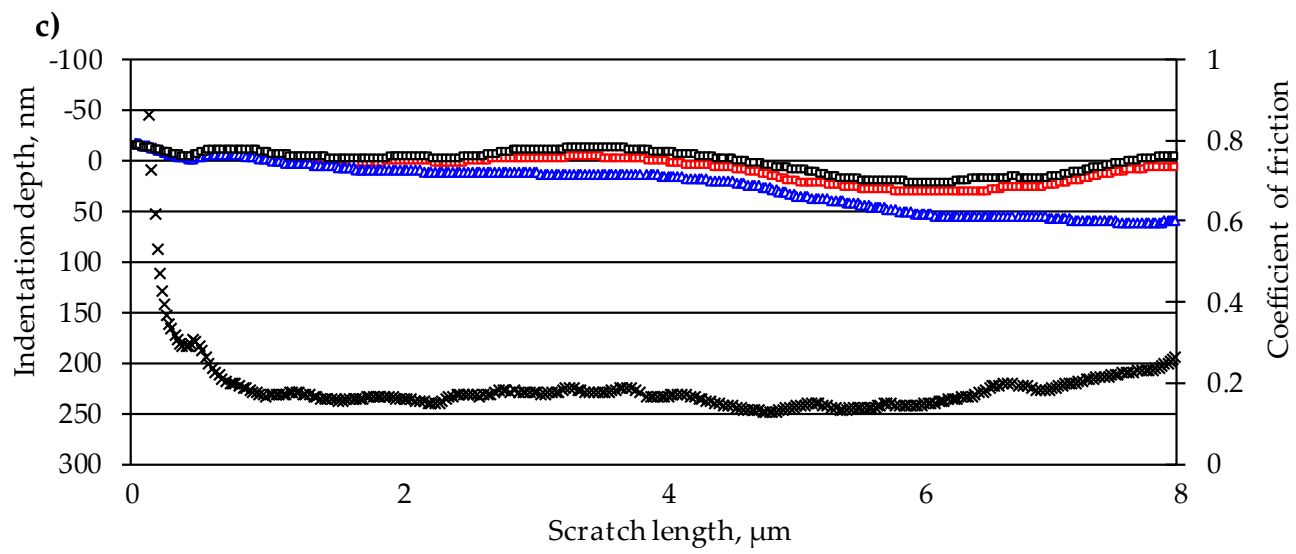

Figure 8. Results of the scratch tests: (a) industrial bearing washer made of conventional rolling bearing steel AISI 52100; (b) hybrid bearing washer without additional deformation; (c) hybrid bearing washer with additional deformation.

The microtribological investigations show a very similar $\mathrm{CoF}$ of approx. 0.3 for the hybrid bearing washers. This can be explained by the same low-alloy quenched and tempered steel AISI 5140 of the cladding. The comparison of the industrial bearing with the hybrid bearing with additional forming shows a similar plastic material behaviour of the surface. On the contrary, the hybrid bearing washer without additional forming shows a significantly higher affinity to plastic deformation.

\section{Scanning Ultrasonic Microscopy (SAM)}

In order to examine the quality of the joining zone before the fatigue test, a non-destructive inspection using scanning acoustic microscopy (SAM) (PVA TePla Analytical Systems GmbH, Westhausen, Germany) in the ultrasonic frequency range was carried out. This method enables tomographic imaging of material defects or pores in the joining zone of tailored forming components. The washer was placed in a bath with distilled water, which serves as a coupling medium for the ultrasonic signal. Ultrasonic pulses are generated and received in the transducer-receiver unit of the ultrasonic microscope. The runtime signal is influenced by cracks, inclusions and pores, which can be measured as a change in the material dependent speed of sound.

Bearing washers prior and after forging were analysed on a modified PVA TePla SAM 301 system (PVA TePla Analytical Systems GmbH, Westhausen, Germany). Two different transducers, as depicted in Table 4, were used. After welding, the C-Scans of the washer showed indications in a depth of $2.5 \mathrm{~mm}$ from the component surface, which corresponds approximately to the position of the joining zone. These indications were identified as circularly arranged pores aside the welding seams with a typical size of $10 \mu \mathrm{m}$, up to $20 \mu \mathrm{m}$ (see Figure 9a). Figure $9 \mathrm{~b}$ depicts a bearing washer after forging, showing only a few very small pores. In comparison, the number of pores due to the welding process was reduced drastically.

Table 4. Parameters for ultrasonic microscopy.

\begin{tabular}{cccc}
\hline Frequency & Focal Length in Water & Axial Resolution & Detection Limit \\
\hline $30 \mathrm{MHz}$ & $12.7 \mathrm{~mm}$ & $13.68 \mu \mathrm{m}$ & $6.59 \mu \mathrm{m}$ \\
$110 \mathrm{MHz}$ & $8 \mathrm{~mm}$ & $19.78 \mu \mathrm{m}$ & $4.56 \mu \mathrm{m}$ \\
\hline
\end{tabular}



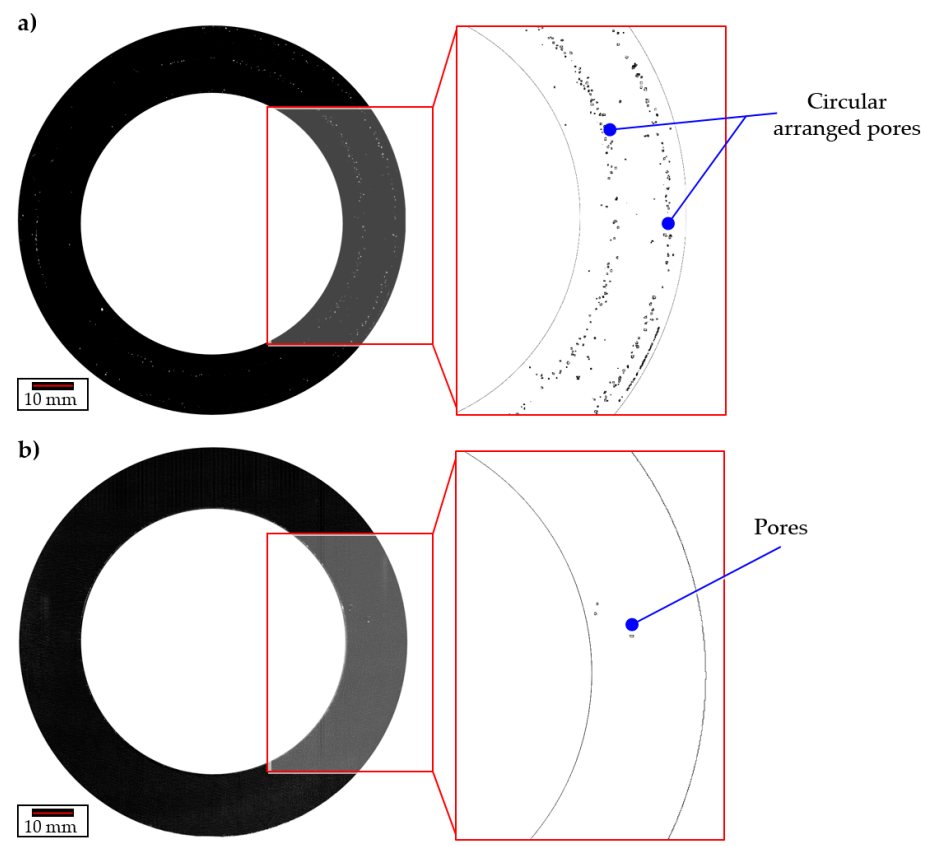

Figure 9. Scanning ultrasonic microscopy of a tailored forming bearing washer: (a) after joining and before forging, showing subsurface pores aside the welding lines (indicated as white spots), (b) after forging, showing a reduction of subsurface pores (indicated as white spots); zoom images edited by inverting the color range.

\section{Tribological Investigations}

After proving the surface integrity, fatigue life tests were carried out. In order to achieve the required boundary zone properties like a surface roughness of $R_{\mathrm{a}}<0.14 \mu \mathrm{m}$, the bearing washers were hard turned after hardening. Before testing, the bearing washers were assembled with a conventional plastic cage made from glass fibre reinforced polyamide and rollers, see Figure 10a. The dimension of the bearing washer is based on type 81212 with a modified washer thickness of $7 \mathrm{~mm}$. For the investigation of the tailored forming bearings under rolling contact load, a FE- 8 rig (Figure 10b) was used.

(a)

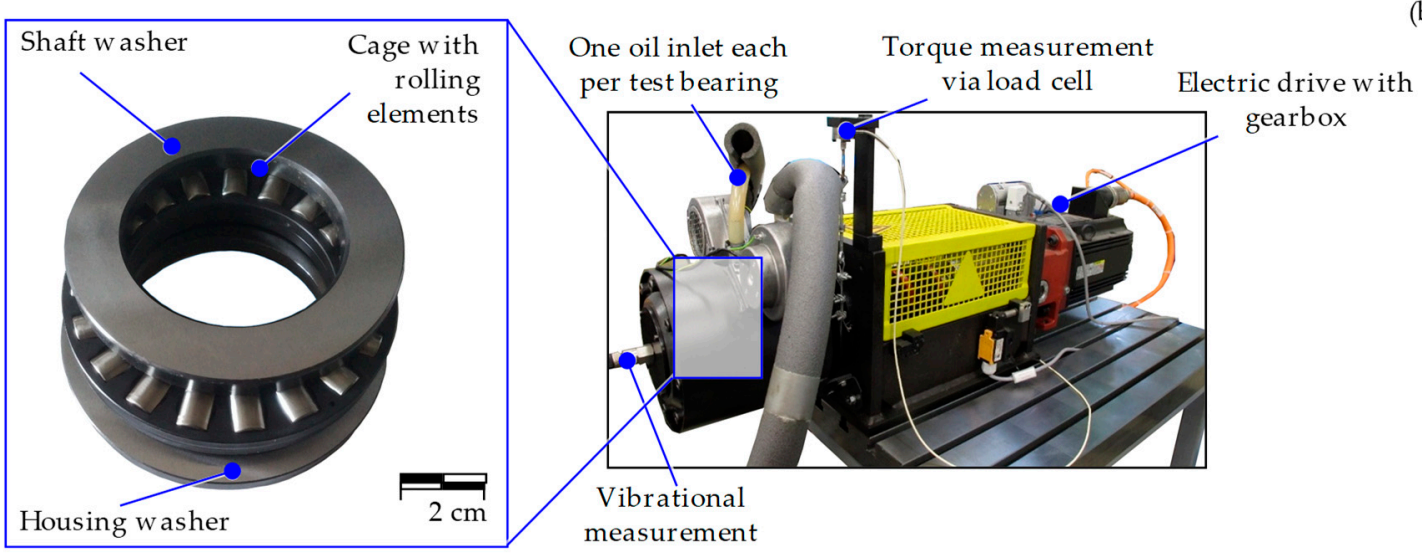

Figure 10. Assembled bearing consisting of tailored forming bearing washers, cage, and rollers (a); FE8 rig for investigation of fatigue of two tailored forming bearings simultaneously (four washers per test, (b).

The test setup is conventionally used for the dynamic-mechanical testing of rolling bearing lubricants [22]. The procedure is regulated in the DIN 51819 standard. The test was carried out with 
lubricating oil at $70{ }^{\circ} \mathrm{C}$ and $250 \mathrm{rpm}$ (cf. [7]). To stabilize the bearing temperature, the test head was cooled by convection. A preload of $40 \mathrm{kN}$ was applied to the hybrid bearings via disc springs. The load is imposed via a hydraulic press, whereby the axial force is measured with a force transducer HBM C2 (nominal force $100 \mathrm{kN}$ ) and a carrier frequency amplifier HBM SCOUT55 (Hottinger Baldwin Messtechnik GmbH (HBM), Darmstadt, Germany). The test run was monitored by vibration measurement and shut down if a limit level of $150 \%$ of the steady state signal was exceeded. Each test run consists of two bearing assemblies; i.e., a total of four hybrid washers and two cages including rollers were used per test run (cf. Figure 10a). Twenty thrust bearing washers were investigated in five test runs. The tests were carried out according to the sudden death strategy, in which all bearings are replaced after the failure of the first bearing of a test run. In the following, the minimal test durations of the failed bearing washer are examined.

In a first step, bearing washers, which were not forged after the cladding process were tested in the FE8 test rig. Figure 11 shows a bearing washer after failure (after $237 \mathrm{~h}$ test duration). Multiple small breakouts (pittings) are visible on the surface, which correspond with the circularly arranged pores seen in the SAM analyses (Figure 9). Figure 12 also shows a detailed view of a surface damage, which has a depth of approx. $160 \mu \mathrm{m}$.

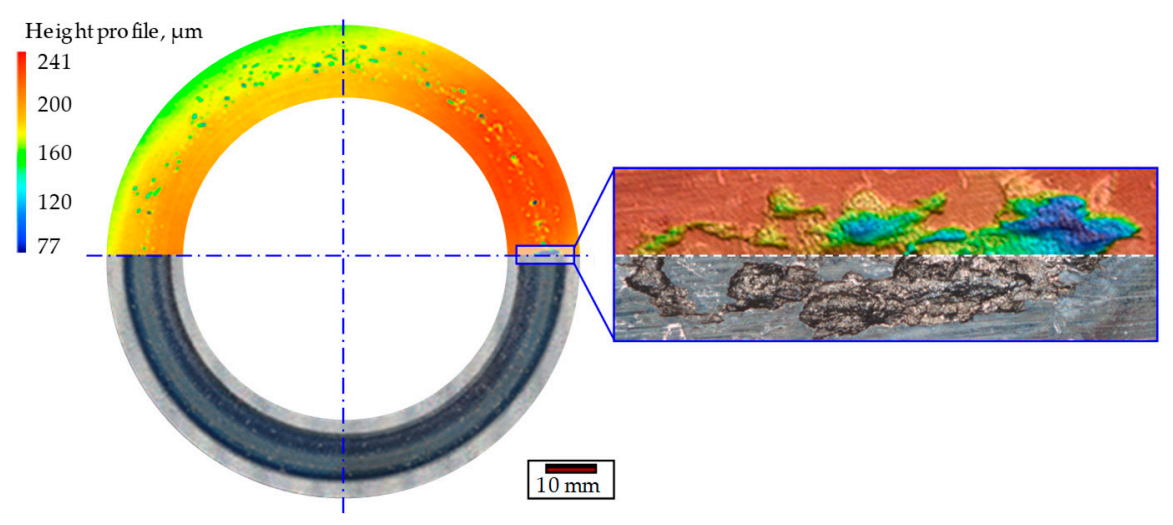

Figure 11. Bearing washers which were not forged after the cladding process after rolling contact load test (running time of $237 \mathrm{~h}$ ).

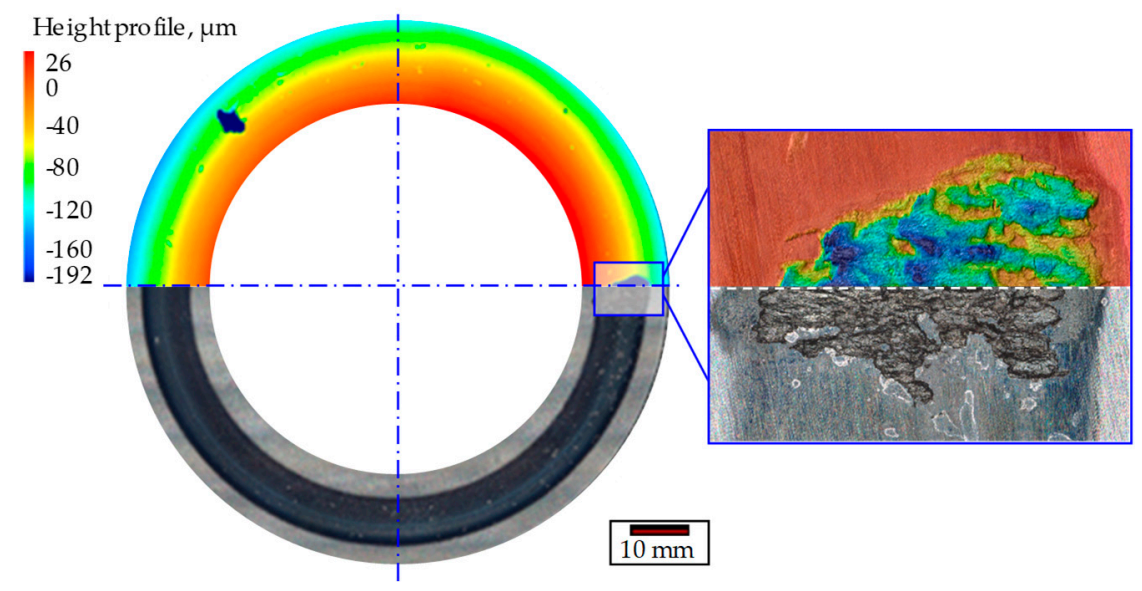

Figure 12. Tailored forming bearing washer after rolling contact load test (running time of $332 \mathrm{~h}$ ).

In comparison, a tailored forming bearing washer was prone to the same test conditions in the FE8 rig. The first test showed that the tailored forming axial bearing washers have running times of more than $330 \mathrm{~h}$, which is nearly comparable to those of industrial bearings made of AISI 52,100 (up to $390 \mathrm{~h}$ ). Figure 12 shows a bearing washer after $332 \mathrm{~h}$ of operation. The detailed view shows 
surface damage with a pitting depth of approx. $220 \mu \mathrm{m}$. It can be concluded that the failure is a normal fatigue damage as the depth of the failure is within the range of the max. load induced stresses.

\section{Conclusion and Outlook}

In this paper, load-adapted samples for use as rolling element bearings were investigated which were produced by deposition welding, subsequent forming and final finishing. Metallographic investigations have shown that the component properties can be significantly improved by a subsequent forming step. By the forging of tailor-made discs, the subsurface pores were reduced drastically, which makes this approach feasible and improves the operational behavior of the parts. The test results of the fatigue life tests and the metallographic analyses confirm the advantages of the tailored forming approach. The structure of the cladding features grain refinement after forging and now has a microstructure similar to that of AISI 5140 monomaterial. Compared to the fatigue life tests of the industrial bearings made of AISI 52100, comparable running times of $332 \mathrm{~h}$ (industrial bearings: $390 \mathrm{~h}$ ) were achieved on an FE8 test rig by investigating ten sets of hybrid bearings (i.e., 20 hybrid thrust bearing washers with conventional cage and rollers). The hybrid axial bearing washers, which were manufactured without subsequent forming, only achieved a running time of $237 \mathrm{~h}$ compared to the other bearings.

By applying further improved alloys as deposition material, it is expected to enhance the bearing fatigue life, although the primary goal is to provide a process to achieve machine elements where tailored properties are integrated by using the right material on discrete machine zones according to the demands. This process can be applied also on radial bearings by applying PTA with a subsequent cross-wedge rolling process (i.e., [2,23]). This enables them to be used as bearings under typical loads. It is to be expected that the performance of the bearings can be further increased by ongoing process optimisations.

Author Contributions: H.J.M., T.H. and M.M. developed the welding process to produce large-area and crack-free deposition welds on steel discs. They also supervised the preparation of the metallographic sections and carried out the microstructure analysis; G.P., F.P. and T.C. developed the components and supervised the production. They carried out the ultrasonic tests as well as tribological investigation including the endurance tests of the finished components with final evaluation; B.-A.B., A.C. and T.M. carried out the necessary forming tests and microscopic analyses before/after the forming process as well as before/after the endurance tests including the damage analysis. In addition, they carried out the microtribological examinations. M.M., T.C. and T.M. wrote the paper.

Funding: This research was funded by the Deutsche Forschungsgemeinschaft (DFG, German Research Foundation) grant number 252662854. The APC was funded by the Deutsche Forschungsgemeinschaft (DFG, German Research Foundation).

Acknowledgments: The results presented in this paper were obtained within the Collaborative Research Centre 1153 "Process chain to produce hybrid high performance components by Tailored Forming" in the subprojects A04, C01 and C03, funded by the Deutsche Forschungsgemeinschaft (DFG, German Research Foundation) - 252662854. The authors thank the German Research Foundation (DFG) for their financial support of this project. The subsequent processing steps to complete the hybrid component, such as heat treatment and machining, were carried out by subprojects A02 and B04.

Conflicts of Interest: The authors declare no conflict of interest.

\section{References}

1. Politis, D.J.; Jianguo, L.; Dean, T. Investigation of material flow in forging bi-metal components. In Proceedings of the 14th International Conference on Metal Forming, Krakow, Poland, 16-19 September 2012; pp. 231-234.

2. Blohm, T.; Mildebrath, M.; Stonis, M.; Langner, J.; Hassel, T.; Behrens, B.-A. Investigation of the cladding thickness of plasma-transferred arc deposition welded and cross wedge rolled hybrid parts. Prod. Eng. 2017, 11, 255-263. [CrossRef]

3. Mildebrath, M.; Blohm, T.; Hassel, T.; Stonis, M.; Langner, J.; Maier, H.J.; Behrens, B.-A. Influence of cross wedge rolling on the cladding quality of plasma-transferred arc deposition welded hybrid steel parts. Int. J. Emerg. Technol. Adv. Eng. 2017, 7, 1-7. 
4. Mildebrath, M.; Coors, T.; Barroi, A.; Pape, F.; Lammers, M.; Hermsdorf, J.; Overmeyer, L.; Poll, G.; Hassel, T. Herstellungsprozess und wälzfestigkeit von hybriden hochleistungsbauteilen. Konstruktion 2018, 9, 84-89.

5. Behrens, B.-A.; Bouguecha, A.; Bonk, C.; Bonhage, M.; Chugreeva, A.; Matthias, T. FE-based design of a forging tool system for a hybrid bevel gear. Key Eng. Mater. 2017, 742, 544-551. [CrossRef]

6. Chugreeva, A.; Bouguecha, A.; Behrens, B.-A. Production Chain of Hot-Forged Hybrid Bevel Gears from Deposition-Welded Blanks. In Proceedings of the 7 WGP-Jahreskongress, Apprimus Verlag, Aachen, Germany, 5-6 October 2017; pp. 21-28.

7. Pape, F.; Coors, T.; Barroi, A.; Hermsdorf, J.; Kaierle, S.; Matthias, T.; Bonk, C.; Chugreeva, A.; Bouguecha, A.; Mildebrath, M.; et al. Tribological Investigations on Tailored Formed Axial Bearing Washers. In Proceedings of the 6th World Tribology Congress, Beijing, China, 17-22 September 2017; p. 22.

8. Stanford, M.K.; Jain, V.K. Friction and wear characteristics of hard cladding. Wear 2001, 251, 990-996. [CrossRef]

9. Ringsberg, J.W.; Skyttebol, A.; Josefson, B.L. Investigation of the rolling contact fatigue resistance of laser cladded twin-disc specimens. Int. J. Fatigue 2005, 27, 702-714. [CrossRef]

10. Cento, P.; Dareing, D.W. Ceramic materials in hybrid ball bearings. Tribol. Trans. 1999, 42, 707-714. [CrossRef]

11. Wan, G.T.Y.; Gabelli, A.; Ioannides, E. Increased performance of hybrid bearings with silicon nitride balls. Tribol. Trans. 1997, 40, 701-707. [CrossRef]

12. Dill, J.F. Hybrid bearing technology for advanced turbomachinery. J. Eng. Gas Turbines Power 1996, 118, 173-178. [CrossRef]

13. Bach, F.W.; Laarmann, A.; Möhwald, K.; Wenz, T. Moderne Beschichtungsverfahren; Wiley-VCH Verlag GmbH \& Co. KGaA: Weinheim, Germany, 2005; pp. 292-305. ISBN 9783527309771.

14. Torims, T. The application of laser cladding to mechanical component repair, renovation and regeneration. Daaam Int. Sci. Book 2013, 12, 587-608.

15. Dilthey, U. Schweißtechnische Fertigungsverfahren 2-Verhalten der Werkstoffe beim Schweißen; Springer: Berlin, Germany, 2005; p. 130. ISBN 978-3540216742.

16. Motallebzadeh, A.; Atar, E.; Cimenoglu, H. Raman spectroscopy characterization of hypo-eutectic CoCrWC alloy tribolayers. Ind. Lubr. Tribol. 2016, 68, 515-520. [CrossRef]

17. Ferozhkhan, M.M.; Duraiselvam, M.; Ganeshkumar, K.; Ravibharath, R. Plasma transfered arc welding of stellite 6 alloy on stainless steel for wear resistance. Procedia Technol. 2016, 25, 1305-1311. [CrossRef]

18. Sawant, M.S.; Jain, N.K. Investigations on wear characteristics of Stellite cladding by micro-plasma transferred arc powder deposition process. Wear 2017, 378-379, 155-164. [CrossRef]

19. Deng, X.; Zhang, G.; Wang, T.; Ren, S.; Bai, Z.; Cao, Q. Investigations on microstructure and wear resistance of Fe-Mo alloy cladding fabricated by plasma transferred arc cladding. Surf. Coat. Technol. 2018, 350, 480-487. [CrossRef]

20. Behrens, B.-A.; Overmeyer, L.; Barroi, A.; Frischkorn, C.; Hermsdorf, J.; Kaierle, S.; Stonis, M.; Huskic, A. Basic study on the process combination of deposition welding and subsequent hot bulk forming. Prod. Eng. 2013, 7, 585-591. [CrossRef]

21. Pape, F. Mikrotribologische Untersuchungen an Wälzlagern mit polymeradditiver Fettschmierung; Tewiss Verlag: Hannover, Germany, 2011; ISBN 9783943104158. (In German)

22. DIN 51819: Mechanisch-dynamische Prüfung auf dem Wälzlagerschmierstoff-Prüfgerät FE8-Teil 3: Verfahren für Schmieröl, Einzusetzende Prüflager, Axialzylinderrollenlager; Beuth Verlag: Berlin, Germany, 2005. (In German)

23. Coors, T.; Pape, F.; Poll, G. Bearing Fatigue Life of a Multi-Material Shaft with an Integrated Raceway. In Proceedings of the Bearing World 2018, Kaiserslautern, Germany, 8 March 2018; pp. 23-30.

(C) 2019 by the authors. Licensee MDPI, Basel, Switzerland. This article is an open access article distributed under the terms and conditions of the Creative Commons Attribution (CC BY) license (http://creativecommons.org/licenses/by/4.0/). 